\title{
Synthesis and Characterization of hen egg albumin and Gelatin composite cross linked with Glutaraldehyde
}

\author{
U. Venkateswarlu \\ Senior Scientist, Advanced Materials Lab, Central Leather Research Institute, \\ Adyar, Chennai-600020, India \\ Email: venkateswaralu@clri.res.in,vummadisetty@gmail.com
}

\begin{abstract}
Hen egg (A), Gelatin (G) and their composite (AB) in film form was prepared in different proportions and cross linked with glutaraldehyde (GTA) and the composite was named as (AGG). The characterization of the composite (AGG) was evaluated with GTA interms of tensile strength. The structure and properties of AGG composite was studied for its FTIR, TGA, CD and mechanical strength. From the results obtained from above studies, it was evident that the cross linked AGG film exhibits higher Tensile strength than uncrosslinked AG films. Thermal decomposition studies show AG was stable up to $375^{\circ} \mathrm{C}$. The $\mathrm{CD}$ spectrum shows an unordered random coil to AGG and helical structure for A, G, AG composites which shows confirmation of crosslinking of AG with GTA.
\end{abstract}

Keywords: hen egg albumin, Gelatin, Glutaraldehyde, Tensile strength, FTIR, CD, TGA

\section{INTRODUCTION}

Hen egg white a cytoplasm of egg is a single cell until fertilization. Gelatin cross linked with glutaraldehyde finds applications in determination of $\alpha$-amylase activity and $\beta$-galactosidase. In our previous study [1] we synthesized a binder using egg white with gelatin. In this study we cross linked AG composite with glutaraldehyde and characterized for its physical \& chemical properties. Bovine serum albumin cross linked with glutaraldehyde was used by Hidas [2] as bio glue in tissue as an adhesive and also as a sealing agent for kidney during partial nephrectomy. Similarly albuminglutaraldehyde glue was used as a tissue adhesive for sealing pulmonary parenchyma and bronchial anatomizes by Georg [3]. The composite developed by Kamalrookh [4] uses Egg white which is cross linked with glutaraldehyde has been used for continuous analysis of bacterial cell. The property of hen egg white cross linked with Lysozyme was reported by Marolia [5] that used in immobilization of Lysozyme. Anandrao [6] has developed a new interpenetrating polymeric network of sodium alginate, gelatin, egg white cross linked with glutaraldehyde used for in-vitro release of cefadroxil. Bigi [7] studied mechanical, thermal, swelling properties of glutaraldehyde cross-linked gelatin films. Tabata [8] has prepared biodegradable gelatin cross linked glutaraldehyde hydrogels and implanted the same in rats to find neovascularization of bFGF release. Yan Changhong [9] has prepared anticancer composite using glutaraldehyde cross linked microspheres and quantified the in-vitro release of drug.
Jitendra Sharma [10] has reported on Laser light scattering of gelatin - glutaraldehyde film for static \& dynamic studies. Kennedy [11] has studied surface immobilization and entrapping of enzymes on glutaraldehyde cross linked gelatin films. Creep behavior of glutaraldehyde cross linked gelatin was evaluated by Martucci [12].

\section{MATERIALS \& METHODS 2.1. Materials}

Hen egg white was separated from chicken egg and used as such. Gelatin from MBD, Mumbai, India was used as such. Glutaraldehyde was obtained from Merck, Germany and used as such. All other reagents used were of analytical grade.

\subsection{Methods}

2.2.1. Preparation of Albumin solution (A)

Isolated hen egg white was kept in a conical flask and denoted as (A).

2.2.2. Preparation of Gelatin solution $(G)$

$20 \mathrm{gm}$ of gelatin powder was dissolved in $200 \mathrm{ml}$ distilled water at $55^{\circ} \mathrm{C}$ in a water bath for about $3 \mathrm{hr}$, cooled and stored in a conical flask and is denoted as (G).

2.2.3. Preparation of AG film

$5 \mathrm{ml}$ of Albumin solution (A) was added to $20 \mathrm{ml}$ gelatin solution at the ratio of $1: 4$ and the mixture is stirred thoroughly and poured in to a polythene tray and dried as mentioned in our earlier study [1]. This ratio has given better results in our earlier study and the film so formed is designated as (AG). 


\section{Available online at www.ijrat.org}

\subsubsection{Cross linking of $A G$ with Glutaraldehyde (AGG)}

$30 \mathrm{ml}$ of solution (A) was added to $120 \mathrm{ml}$ of solution (G) and the mixture is divided into six equal parts of 20 $\mathrm{ml}$ each and marked as I, II, III, IV, V and VI. Known amount of glutaraldehyde namely $0.25 \mathrm{ml}, 0.5 \mathrm{ml}, 0.75$ $\mathrm{ml}, 1.0 \mathrm{ml}, 1.25 \mathrm{ml}$ and $1.5 \mathrm{ml}$ respectively) was added to the above six solutions (AG) and mixed thoroughly and poured in to six polyethylene trays and dried as mentioned earlier. These films are denoted as AGG.

\section{CHARACTERIZATION}

\subsection{Tensile strength}

The samples AG and AGG were characterized for their Tensile strength using INSTRON 1405 according to Vogel [11] at speed of $5 \mathrm{~mm} / \mathrm{min}$. Two dumbbell shaped specimens of $4 \mathrm{~mm}$ wide and $10 \mathrm{~mm}$ length were punched out using a die. Mechanical properties such as Tensile strength $(\mathrm{MPa})$ and elongation $(\%)$ were measured.

\subsection{FTIR Spectroscopy}

To provide proof of cross linking of glutaraldehyde with AG we have taken FTIR spectra of AG and AGG using Nicolet Impact 400 using a $500 \mathrm{mg} \mathrm{KBr}$ pellet containing 2-6 mg of the sample.

\subsection{Circular Dichroism Spectroscopy}

The CD measurements were recorded on a JASCO J715 spectropolarimeter, Japan. The instrument was calibrated using Ammonium-d10-camphor sulfonic acid as described by the manufacturer. The path length used was $1 \mathrm{~mm}$. The spectra were recorded with $1 \mathrm{~nm}$ bandwidth and $0.2 \mathrm{~nm}$ step resolution. The CD spectra represent an average value from five readings. The resulting spectra were baseline-corrected and smoothened. The samples AG and AGG were obtained by dissolving $0.5 \mathrm{ml}$ of the sample in $10 \mathrm{ml}$ of distilled water. All the spectra were collected from 190-250 nm range which is a suitable bandwidth to study the secondary structure of most of the proteins and peptides.

\subsection{Thermal gravimetric Analysis}

Thermal stability of the films was determined with a thermo gravimetric (TG) Analyzer (Perkin-Elmer TGA) over a temperature range of $37^{\circ} \mathrm{C}-585^{\circ} \mathrm{C}$ at a heating rate of $20^{\circ} \mathrm{C} / \mathrm{min}$ under Nitrogen atmosphere.

\section{RESULTS \& DISCUSSION \\ 4.1 Tensile Strength}

Tensile strength of samples of different proportions AG and GTA was given in below Table.1.

Table.1. Tensile strength of AGG

\begin{tabular}{|c|c|c|c|c|}
\hline S. No. & AG $(\mathrm{ml})$ & GTA $(\mathrm{ml})$ & $\begin{array}{c}\text { Tensile strength } \\
(\mathrm{MPa})\end{array}$ & $\begin{array}{c}\text { Elongation at brake } \\
(\%)\end{array}$ \\
\hline I & 25 & 0 & 20.9 & 126 \\
\hline II & 25 & 0.25 & 33.3 & 112 \\
\hline III & 25 & 0.5 & 40.0 & 170 \\
\hline IV & 25 & 0.75 & 36.2 & 143 \\
\hline V & 25 & 1.0 & 32.1 & 68 \\
\hline VI & 25 & 1.25 & 28.4 & 45 \\
\hline VII & 25 & 1.5 & 25.2 & 40 \\
\hline
\end{tabular}

Based on our previous study [1] we have prepared a mixture of $A$ and $G$ at a ratio of $1: 4$ which is an optimum AG composite interms of its tensile strength. From above table, it is clear that the Tensile strength of AGG increases initially with glutaraldehyde concentration and then decreased. AG containing $0.5 \mathrm{ml}$ GTA gave better result of tensile strength due to complete reaction of GTA with $\mathrm{NH} 2$ groups in AG composite as shown in Fig.2 where $\mathrm{NH} 2$ in Fig. 1 is vanished. With increase in GTA, it homo polymerizes and hence shows decrease in tensile strength which is shown in fig.3. Due to the homo polymerization, elongation at break was also decreased. The elongation at break for the sample- 3 was also observed as $170 \%$ which is highest among all 


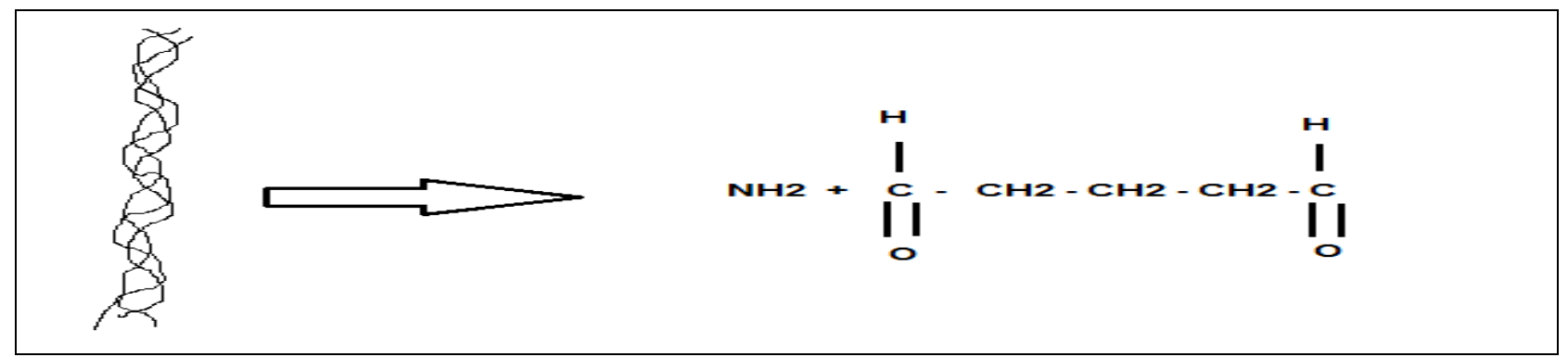

Fig.1. AG composite

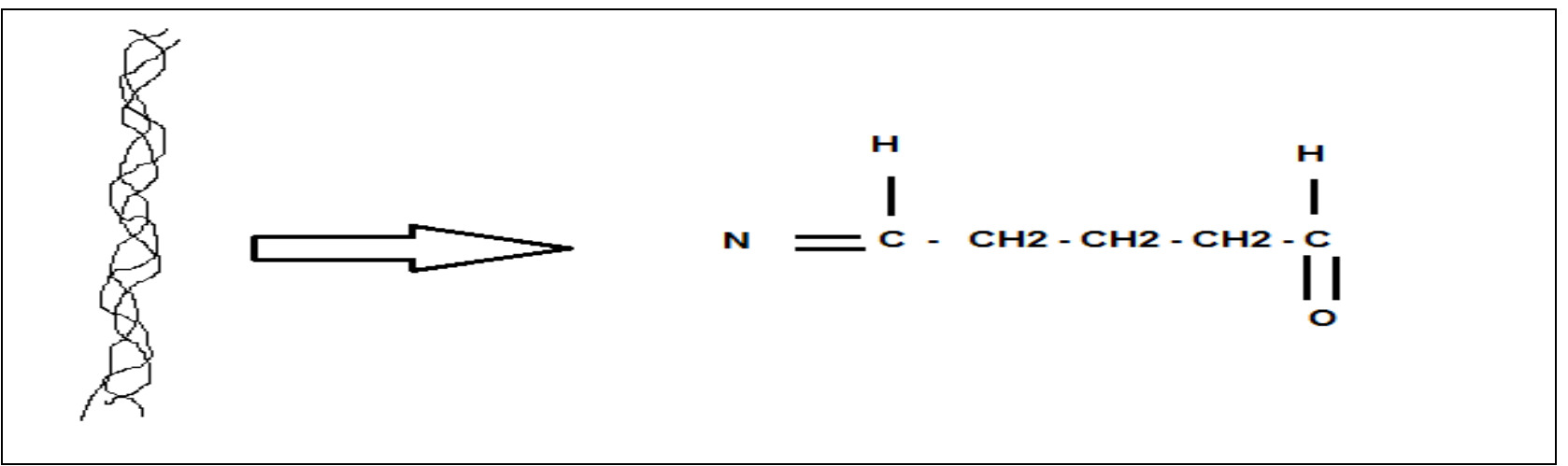

Fig.2. Cross linking of glutaraldehyde

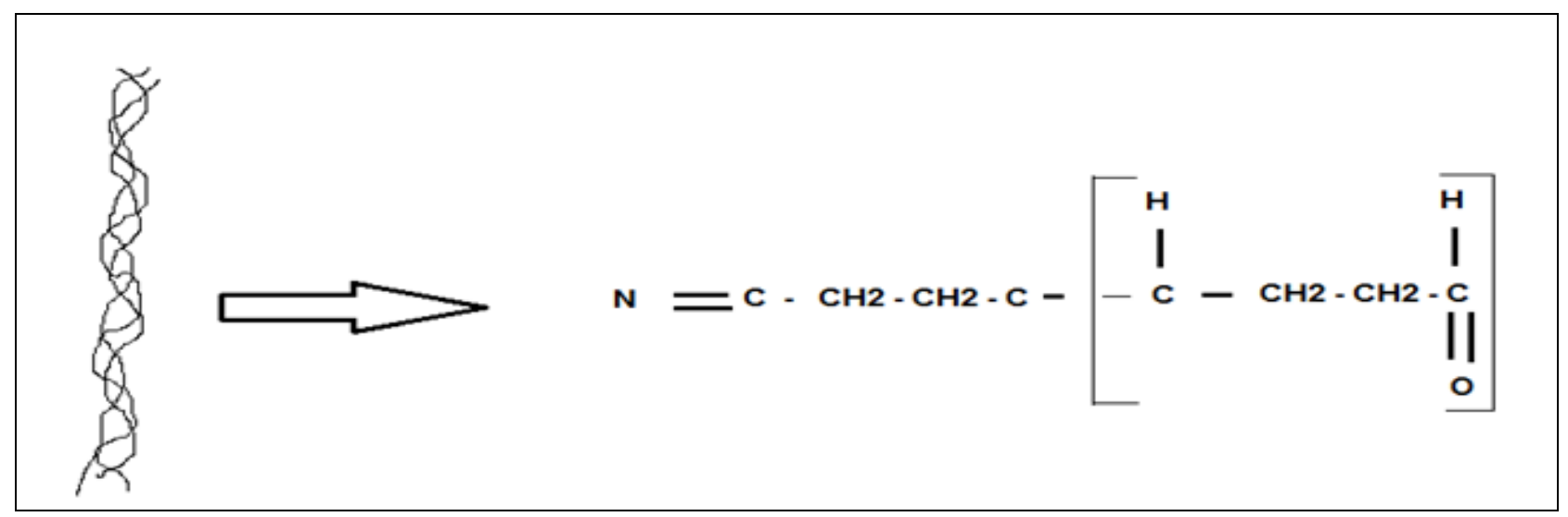

Fig.3. Homo polymerization of glutaraldehyde

\subsection{Water Absorption Test}

Water absorption capacity for all the above prepared samples is shown in below Table.2.

Table.2. Absorption coefficient of AGG

\begin{tabular}{|c|c|c|c|c|c|c|c|c|}
\hline S.No. & Time (hr) & $\begin{array}{c}\text { Sample-1 } \\
(\%)\end{array}$ & $\begin{array}{c}\text { Sample-2 } \\
(\%)\end{array}$ & $\begin{array}{c}\text { Sample-3 } \\
(\%)\end{array}$ & $\begin{array}{c}\text { Sample-4 } \\
(\%)\end{array}$ & $\begin{array}{c}\text { Sample-5 } \\
(\%)\end{array}$ & $\begin{array}{c}\text { Sample-6 } \\
(\%)\end{array}$ & $\begin{array}{c}\text { Sample-7 } \\
(\%)\end{array}$ \\
\hline I & 1 & \multirow{4}{*}{$\begin{array}{l}\text { Disintegrated } \\
\text { after } 1 \mathrm{hr}\end{array}$} & 187 & 213 & 170 & 230 & 157 & 125 \\
\hline II & 2 & & 256 & 213 & 170 & 230 & 157 & 125 \\
\hline III & 3 & & 368 & 230 & 170 & 230 & 157 & 125 \\
\hline IV & 24 & & 300 & 273 & 188 & 240 & 171 & 133 \\
\hline
\end{tabular}


From the above table, it is clear that AG sample as such was disintegrated within a hour whereas samples cross linked with GTA were intact even after $24 \mathrm{hr}$. With increase in GTA concentration, the water absorption capacities were decreased. The hydrophilic groups like $\mathrm{NH} 2, \mathrm{COOH}$ and $\mathrm{OH}$ on $\mathrm{AG}$ backbone would have contributed to the dissolving of the membrane in the water. With the addition of GTA, the NH2 groups on AG would have reacted with $-\mathrm{CHO}$ and increases hydrophobicity. With further increase of GTA, lower values of $\%$ absorption were observed due to homo polymerization of GTA.

\subsection{FTIR Spectroscopy}

FTIR spectra of AG shows protein characteristic peak at $1654 \mathrm{~cm}-1$ (Amide-I) $1561 \mathrm{~cm}-1$ (Amide-II) and $1244 \mathrm{~cm}-1$ (Amide-III) as shown in fig-4. In AGG sample, the Amide band is absent due to cross linking of GTA with AG as shown in fig.5. This confirms the cross linking of GTA with AG.

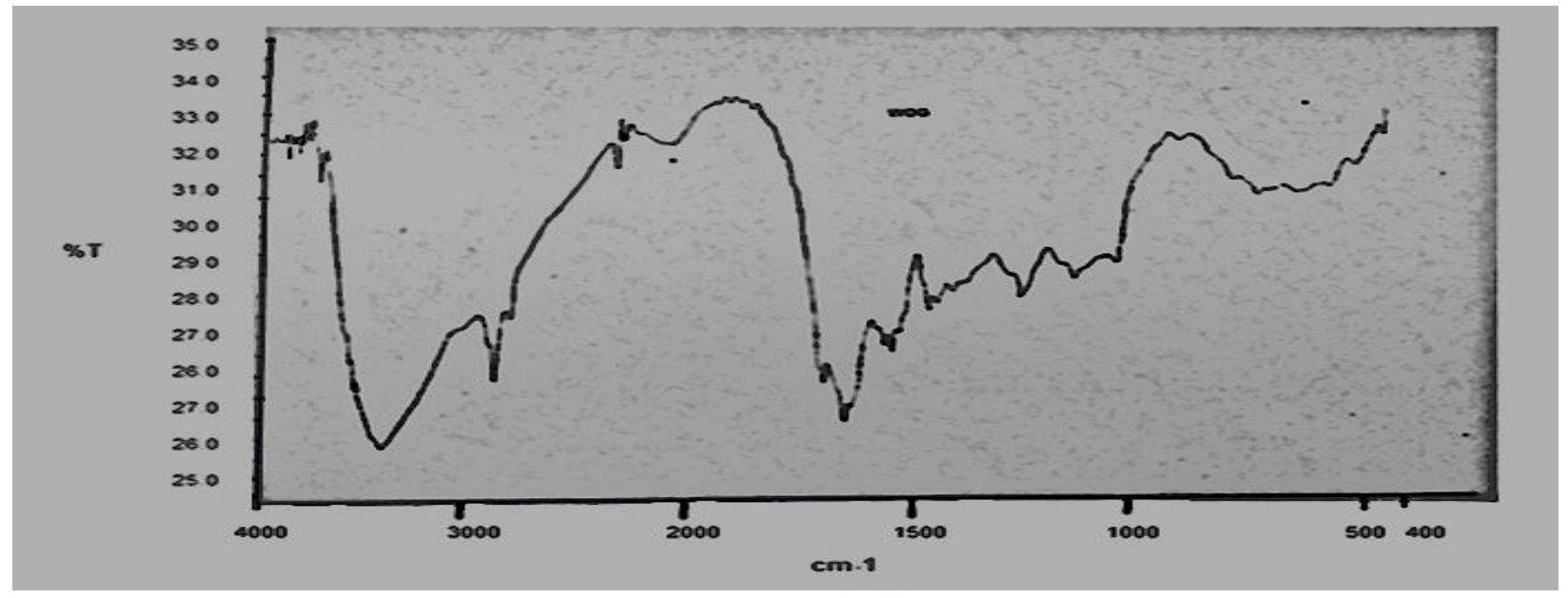

Fig.4. FTIR spectra of AG composite

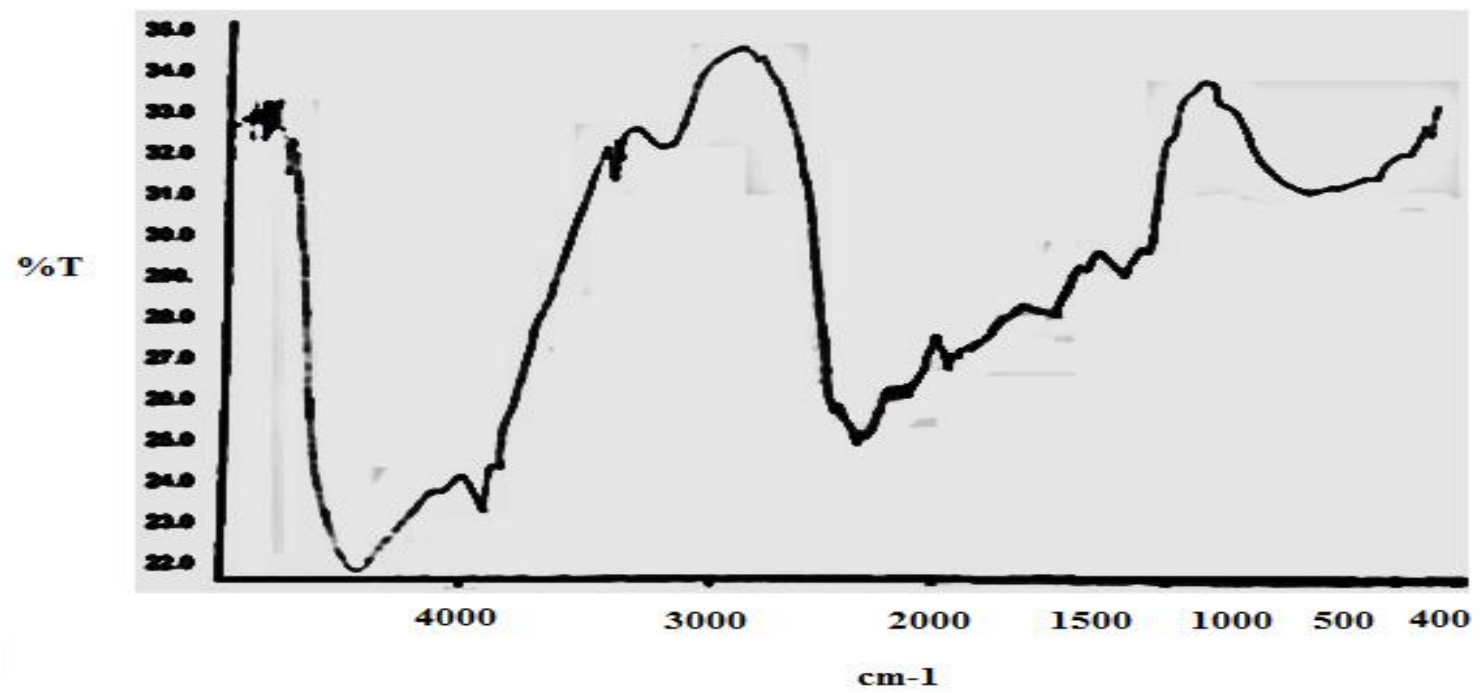

Fig.5. FTIR spectra of AGG composite 
International Journal of Research in Advent Technology, Vol.7, No.1, January 2019

E-ISSN: 2321-9637

Available online at www.ijrat.org

\subsection{Circular Dichroism Spectroscopy}

The far UV spectral studies $(185-250 \mathrm{~nm})$ were conducted on AG and AGG. In our earlier study, we reported that AG composite consists of $\alpha$-helical structure whereas AGG shows random coil structure with negative peak at around $197 \mathrm{~nm}$. This is due to the broken of $\alpha$-helical to random coil structure due to cross linking of GA on to AG. This is shown in fig-6a and fig-6b respectively.

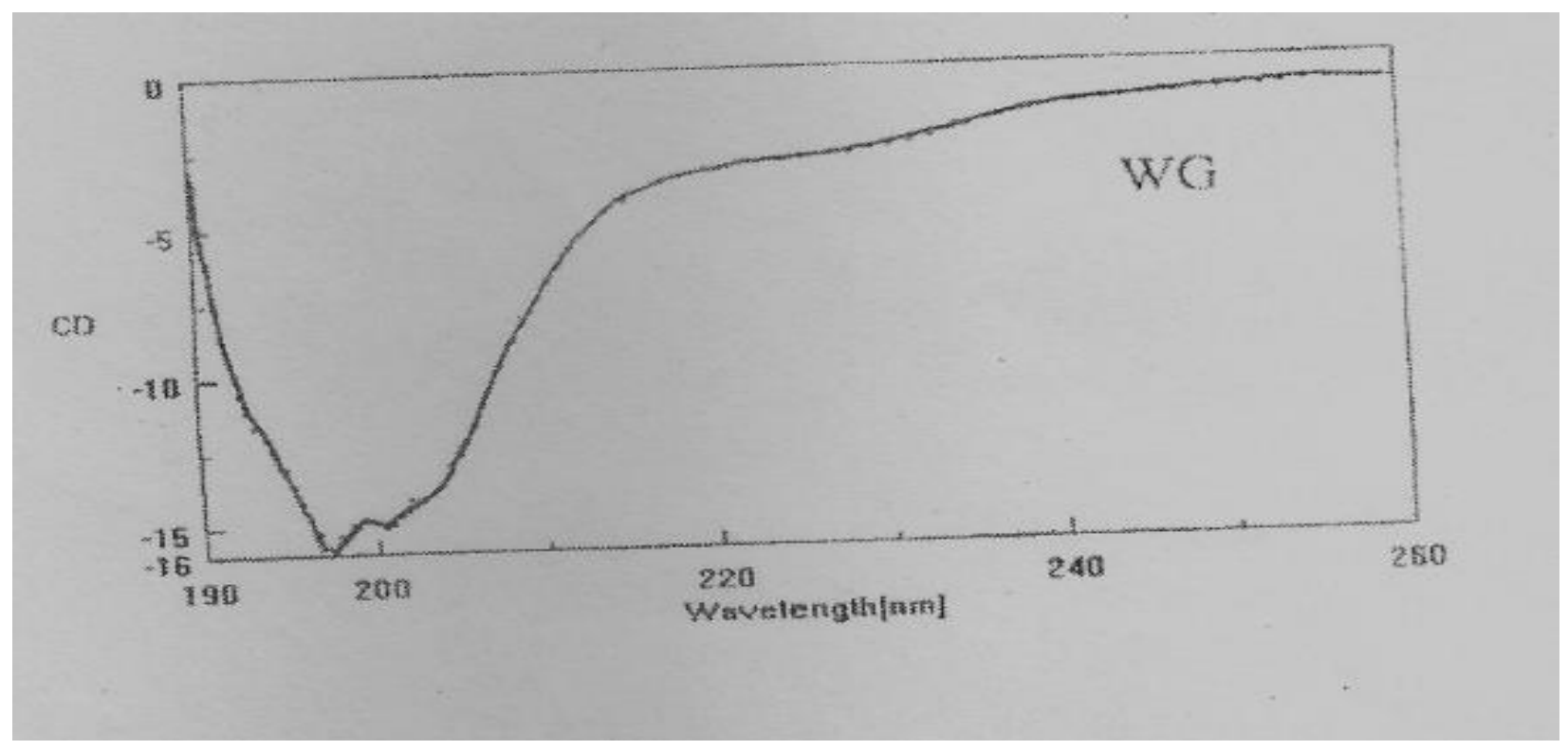

Fig.6a. CD spectra of AGG composite marked as WG

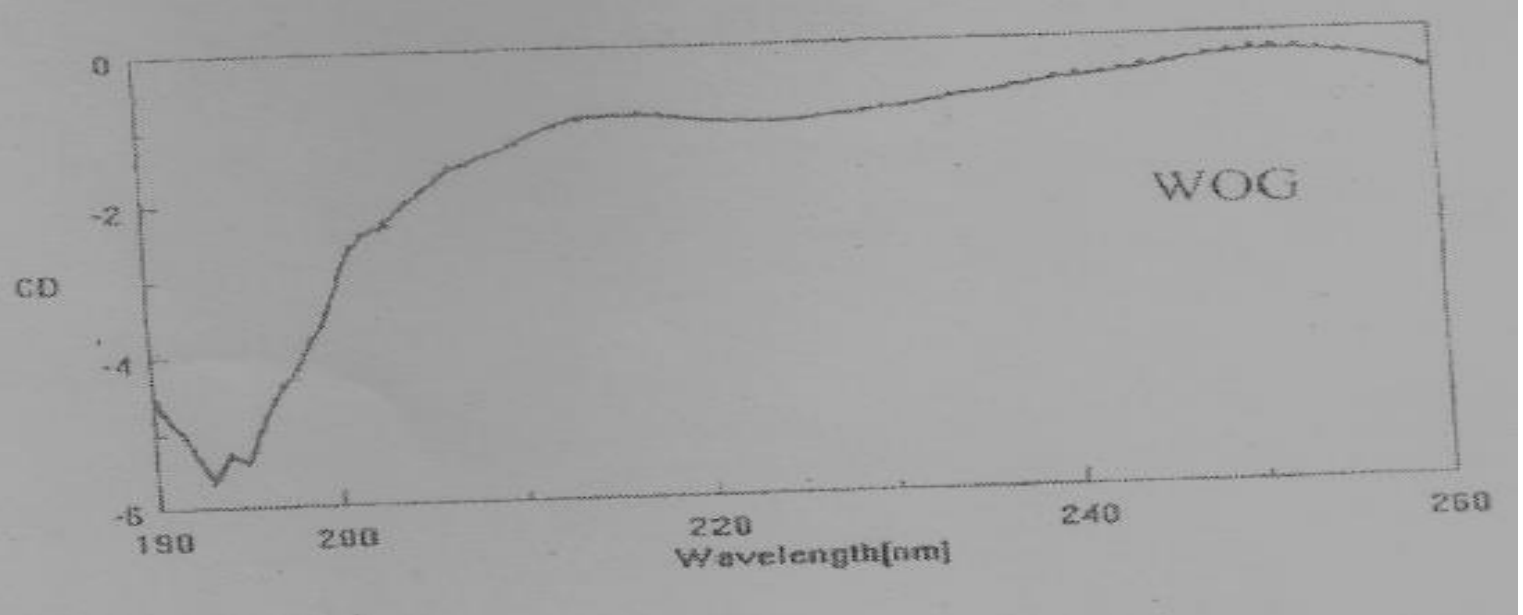

Fig.6b. CD spectra of AG composite marked as WOG 
International Journal of Research in Advent Technology, Vol.7, No.1, January 2019 E-ISSN: 2321-9637

Available online at www.ijrat.org

\subsection{Thermal Gravimetric Analysis (TGA)}

Thermal decomposition profile of AG and AGG shown in fig.7 and fig.8 respectively.

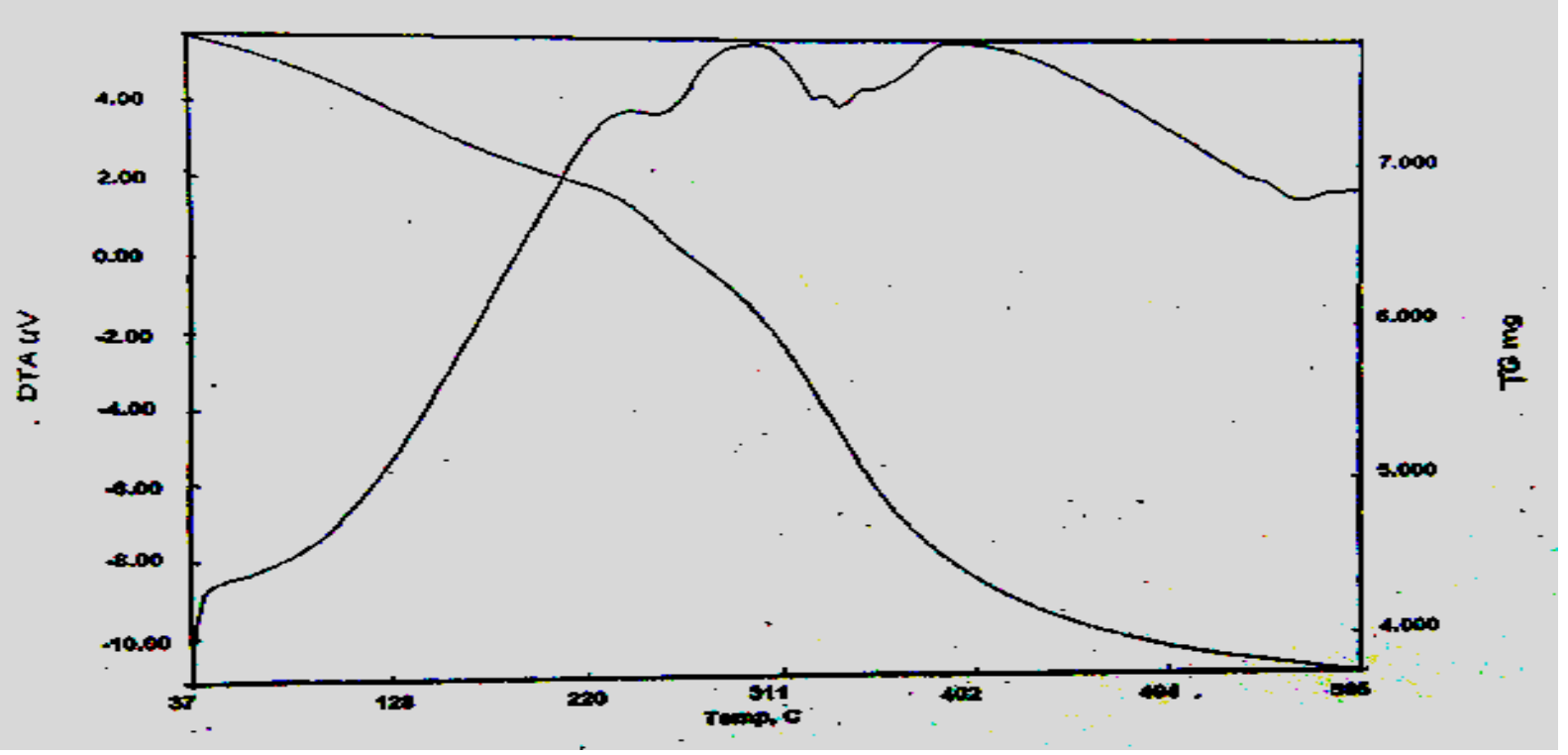

Fig.7. TGA Analysis of AG composite

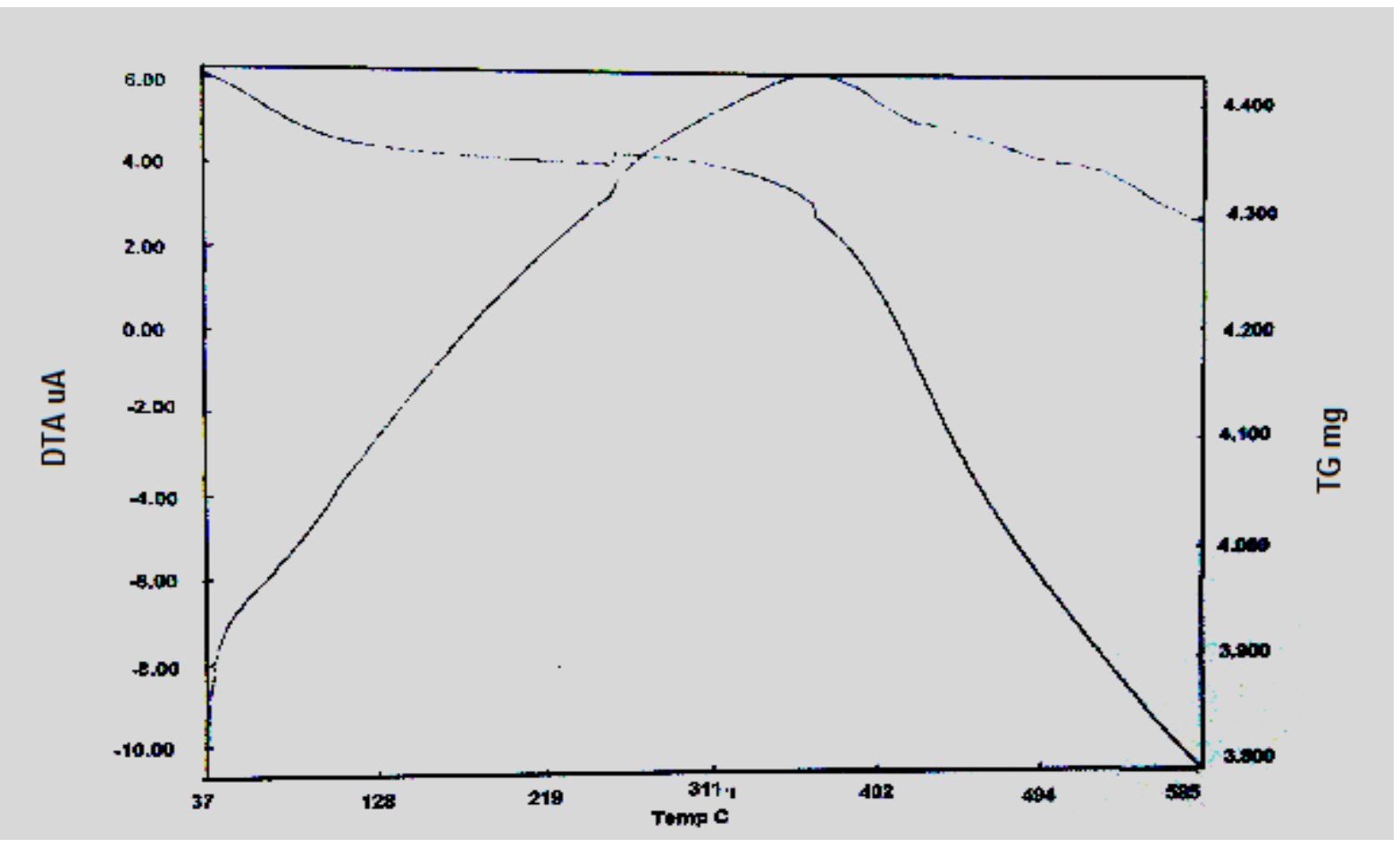

Fig.8. TGA Analysis of AGG composite 


\section{International Journal of Research in Advent Technology, Vol.7, No.1, January 2019 E-ISSN: 2321-9637 \\ Available online at www.ijrat.org}

In TGA analysis, the loss of weight due to evaporation of water and $\mathrm{CO}$ and evaporation of other pyrolysis products are collectively measured as percentage of original weight. In our present study, AG and AGG were heated steadily from $37^{\circ} \mathrm{C}-585^{\circ} \mathrm{C}$. The initial weight loss was observed $\mathrm{f} 25.38 \%$ and $13.08 \%$ were observed at $235^{\circ} \mathrm{C}$ for $\mathrm{AG}$ and $\mathrm{AGG}$ respectively. Above $60 \%$ of weigh loss was observed between $235^{\circ} \mathrm{C}$ to $400^{\circ} \mathrm{C}$ for $\mathrm{AG}$ whereas for $\mathrm{AGG}$ about $8 \%$ of weight loss was observed between $235^{\circ} \mathrm{C}-375^{\circ} \mathrm{C}$. A sudden decomposition was observed between $375^{\circ} \mathrm{C}-585^{\circ} \mathrm{C}$ for AGG. The AGG was thermally stable up to $375^{\circ} \mathrm{C}$ and gradual thermal decomposition was observed from $235^{\circ} \mathrm{C}-585^{\circ} \mathrm{C}$ in case of AG. A $100 \%$ thermal decomposition was observed at $585^{\circ} \mathrm{C}$ for both the samples. The thermal stability of AGG may be due to cross linking of GTA with the functional groups present in backbone of AG.

\section{REFERENCES}

[1] U. Venkateswarlu, Kamala Bhopalan, R. Mohan, B.N. Das and T.P. Sastry. "Studies on chemically modified hen egg white and gelatin composites". Journal of Applied Polymer Science, volume 100, pages 318-322, 2006.

[2] G. Hidas, A. Kastin, M. Mullerad, J. Shental and O. Nativ. "Sutureless nephron-sparing surgery: Use of albumin glutaraldehyde tissue adhesive (BioGlue)". Urology, volume 67, pages 697-700, 2006.

[3] Georg. W. Herget, Mulugeta Kassa, Ursus Nikolaus Riede, Yao Lu and Ludwig Brethner. "Experimental use of an albumin-glutaraldehyde tissue adhesive for sealing pulmonary parenchyma and bronchial anastomoses". European Journal of Cardio-Thoracic Surgery, volume 19, pages 4-9, 2001.

[4] Kamalrookh Z Marolia and Stanislaus F D'Souza. "Enhancement in the lysozyme activity of the hen egg white foam matrix by cross-linking in the presence of N-acetyl glucosamine". Journal of Biochemical and Biophysical Methods, volume 39, pages $115-117,1999$.

[5] Kamalrookh Z. Marolia and S. F. D'Souza. "A simple technique for the immobilization of lysozyme by cross-linking of hen egg white foam". Journal of Biochemical and Biophysical Methods, volume 26, pages 143-147, 1993.

[6] Anandrao R, Kulkarni, Kumaresh S, Soppimath, Tejraj M, Aminabhavi, Walter E and Rudzinski. "In-vitro release kinetics of cefadroxil-loaded sodium alginate interpenetrating network beads". European Journal of Pharmaceutics and
Biopharmaceutics, volume 51, pages 127-133, 2001.

[7] A Bigi, G Cojazzi, S Panzavolta, K Rubini and N Roveri. "Mechanical and thermal properties of gelatin films at different degrees of glutaraldehyde crosslinking". Biomaterials, volume 22, pages 763768, 2001.

[8] Yasuhiko Tabata and Yoshito Ikada. "Vascularization effect of basic fibroblast growth factor released from gelatin hydrogels with different biodegradabilities". Biomaterials, volume 20, pages 2169-2175, 1999.

[9] Yan Changhong, Li Xiongwei, Chen Xiaoli, Wang Danqing and Hiromi Kitano. "Anticancer gelatin microspheres with multiple functions". Biomaterials, volume 12, pages 640-644, 1991.

[10] Jitendra Sharma and H. B. Bohidar. "Gelatinglutaraldehyde supramolecular structures studied by laser light scattering". European Polymer Journal, volume 36, pages 1409-1418, 2000.

[11] J. F. Kennedy, B. Kalogerakis and J. M. S. Cabral. "Surface immobilization and entrapping of enzymes on glutaraldehyde cross linked gelatin particles". Enzyme and Microbial Technology, volume 6, pages 127-131, 1984.

[12] J. F. Martucci, R. A. Ruseckaite and A. Vázquez. "Creep of glutaraldehyde-cross linked gelatin films". Materials Science and Engineering A, volume 435-436, pages 681-686, 2006. 